\title{
ACTION LEARNING: THE NEED FOR ACTION AND REFLECTION FOR MANAGERS AND LEARNERS IN A WORLD OF CHANGE
}

\author{
Jennifer K. Bowerman \\ MacEwan University in Edmonton, Alberta, Canada
}

\begin{abstract}
This paper has been written to inform exactly what action learning is from an organizational change perspective. Following a discussion of the concept based on the work and experiences of its founder Dr. Reg Revans, it reflects on why action learning has an increasingly important application in today's business and management world. Standing in direct contradiction to the normative research usually produced by business school academics, it reflects on the opportunity offered by means of the action learning process to break through established managerial paradigms and theories. It views management (and leadership) as crafts developed through practice and action, as working managers, in cooperation with others, use work based problems as issues to be moved forward on through action and learning. Universities and Business Schools can participate in the process, first by using action learning as a means of building their own expertise, and then working with industries and organizations to develop and recognize work based qualifications as part of an external and valuable accreditation. Finally, the paper ends with important questions that people can begin to use as they initiate their own action learning process to drive their work based issues forward in the change process.
\end{abstract}

Keywords: Action Learning, Management Education, Organizational change.

DOI: http://dx.doi.org/10.15549/jeecar.v5i1.208

\section{INTRODUCTION - “WHEN CHANGE IS GREATER THAN LEARNING, WE ARE IN TROUBLE!"}

The above quote comes from a presentation by Dr. Reg Revans to the students and Faculty of Virginia at a special seminar held 7 at Salford University,was former teaching fellow and experimental physicist who had worked and studied under the tutelage of Lord Rutherford at Cambridge University in the famous Cavendish laboratories. ) He departed his Cambridge studies in 1935 realizing that the world of nuclear physics was not one he could morally participate in. It was left to his physics colleagues in the UK, Germany, and the US to complete that work and take it to its ultimate and deadly conclusion. For their studies, five of his student colleagues won Nobel prizes. Not for Revans however, a Nobel Prize, but rather a huge understanding of the nature of thought. Revans used the processes he had learned at the Cavendish laboratories to transform the British coal industry, the National Health Service, and the Belgium Steel Industry amongst others. In his early days he had the privilege of studying under Albert Einstein and knew Henry Ford personally. Many years later he worked with Nelson Mandela as his contribution to the ending of apartheid.

Revans always remembered a quotation from 
Albert Einstein: "If you think you understand a problem, make sure you are not deceiving yourself." He cited this in many of his presentations including those at Salford and Virginia Commonwealth University because he had studied under Einstein and understood that certainty was always relative. Working with Einstein allowed Revans to develop his thinking on the role of the 'non-expert' in problem solving, distinguishing between knowledge and wisdom. His father had been an insurance investigator for Lloyds of London when the Titanic when down. The builders of the Titanic had the knowledge to build an unsinkable ship. However, they failed to grasp the system in which the ship would be sailing. Knowledge is one thing, implying an association with expertise, whereas wisdom is something else completely, the ability to ask questions from a position of genuine ignorance which can expand thinking, lead to different actions, thereby driving knowledge and learning deeper.

Why did Revans have this overpowering need to build learning and expand thinking? The answer is that his studies in the Cavendish laboratory brought him to the huge understanding that change in our society was happening at such a rate that without a cognitive means of dealing with it, without a means to lead it, we would be swept away. Merely managing change for Revans was insufficient. Harari (2014) demonstrates in his recent book the story of how rapid change has swept our civilization. Fire gave us power;gossip and stories allowed us to to cooperate; agriculture made us hungry;mythology maintained law and order; money gave us something we can trust; contradictions have created culture ... science has made us deadly Perhaps some of this deadly science is tantamount to a rabbit hole we are unable to dig out of. It is visible as we witness the devastation of climate change in the past few months or the rapidly expanding arms race we are experiencing. For Revans the worst thing that could happen was that our learning would not be able to keep up with this kind of change. We must learn not only to manage change butour very survival demands that we lead it.

His famous formula for enabling us to do this was based on the idea that always learning must be greater than the rate of change.

\section{$\mathrm{L}>\mathrm{C}$}

To do this we must reject yesterday's solutions to the problems we are sometimes even unable to address. He called these sticky problems. They were not puzzles to which there was an already known answer. He saw the need to move on, always asking new and fresh questions around the problem, taking actions to address our questions, and through ongoing reflection and action, constantly being directed toward greater understanding, having the capacity to deal with and lead in the changes coming our way. His formula was as follows:

$\mathrm{L}=\mathrm{P}+\mathrm{Q}$ where $\mathrm{L}$ stands for learning, $\mathrm{P}$ stands for programed information we already know, and $Q$ stands for fresh questions about what we don't know - what, how who?

For Revans, there was no mere thinking one's way through a problem. The action part was essential. His prime idea was that "There can be no learning without action, and no (sober and deliberate) action without learning" (Revans, 1998,) He notes that learning can be difficult sometimes even painful - because new knowledge, "while consonant with the scientific method, is inconvenient for other reasons".. The fact is that new paradigms, new modes of thinking are painful and difficult to grasp. We saw this when Galileo challenged classical astronomy by asserting that the planets including the earth circle the sun rather than the sun and other planets circling the earth. Galileo was convicted of heresy for his theory but once it was accepted, it changed our entire way of looking at ourselves and our place in the astronomical order. Today we are witnessing such a paradigmatic shift in health, where journalists, scientists and medical researchers are asking new questions and pulling together new (and old and formally rejected) research which challenges all sorts of preconceived theories of causality around cardiac and diabetic health (Taubes, 2016, Teicholz, 2014). Yet despite their thoroughness, and their commitment to scientific rigour, they are ostracized and met with great hostility by traditional thinkers whose theories dominate the medical and pharmaceutical field. Revans said that Nietzsche had the practice of evaluating any new proposal by the animosity with which it was first received. He writes "Unless it is ridiculed by the clever and opposed by the stupid, it is not worth going ahead with, for it is only after such rough receptions that it 
will be absorbed" (Revans, 1998, p.84).

\section{WHAT DOES THIS HAVE TO DO WITH MANAGEMENT?}

Traditional business schools and universities have had great difficulty in dealing with action learning as a business and organization theory, despite the fact that business and economics have become the foundations of secular modern society. If a business school is unable to address the difficulties of keeping up with change through learning then who else should do it? For example, how have recent hurricanes affected supply chains, decision making, industry? What are the implications for the victims of such tragic events? Who is addressing these questions, if not us? How can we rebuild infrastructure in areas which have been devastated by natural phenomena where a governing criteria for implementation is business as usual, and profit and greed? One former colleague in the field of of hospitality pointed out in a private conversation with the author that there were too many manuals on how to make the hospitality industry efficient in terms of , customer service, housekeeping rules and so on, but insufficient emphasis on what to do in the event of a crisis. Given the extent to which resorts and hotels have been hit by violent cyclones and storms in recent years, particularly in the Caribbean islands, and even the United States, one can only hope that this situation has been rectified.

Revans took a great dislike to traditional business schools when he saw how they corrupted his theories. He despised case studies, (flatulent self-deception) and probably he would have despised the text books university teachers have grown so dependent on. For him, theory and action went hand in hand. "The most precious asset of any organization is the one most readily overlooked; its capacity to build upon its lived experience, to learn from its challenges and to turn in a better performance by inviting all and sundry to work out for themselves what that performance ought to be", (Revans, 1998, p. 134). In other words, we cannot teach an organization how to be and how to improve from the outside looking in. It is just too easy to have the answers for other people. First they have to be given the space and the opportunities to define and ask the questions themselves. For this reason, business schools are lagging behind. They have too often separated wonderful theories from messy practices. When we pretend to teach management, it becomes as Mintzberg says "devoid of craft" over emphasizing analysis (Mintzberg, 2004, p. 95).

Business School researchers have all too often followed this traditional practice. The "publish or perish" idiom has persuaded many business researchers that their best efforts are demonstrated through so called scientific positivistic papers that reflect an ontological orientation. Perhaps we need to ask, What is the craft of the business school teacher' Is there a relationship between our chosen subject and the organization to which we belong i.e. our business school or university? Are we merely teachers and studiers of business or are we simultaneously learners, applying our learning to the very institutions which employ us as well as those outside? 'How can we build action learning into our craft and apply ourselves as actors of change as well as be teachers of the trade and writers about the trade?'

As an editor of major research journal, most of the papers received contain pages and pages of mathematical looking formulas and tables pitting factors to be researched against each other leading to a 'so what?' reaction on the part of the reader. They fail to tell us what the next steps could be and how the research contributes to the real and ever changing chaotic world of real life. Given the research hypothesis of the writer, what actions are possible to drive the organization forward, to make it better and not just for shareholders?

An overarching value to which most of us pay lip service is that of people. Their connections, their motivations, their joys and their sadness all become fuel for understanding how better to improve our understanding of what is happening and how to move forward. This is qualitative research. One method is to use grounded theory to learn from people using their stories. These stories can provide powerful insights into our knowledge of what is really happening -in the organization, in the lives of its employees and in wider society. The questions are simple, "What are people really trying to achieve and what do they worry about? What do they believe about their work and its value? Often we simply do not know. Nor do our positivist and conformist and theory testing methodologies provide too many answers. However, we can use our findings from the 
stories we hear to develop new insights and theories to move us forward. Brene Brown, a social psychologist has used her grounded theory experience to explore the idea that people really desire to be part of something; that in today's world, they are experiencing a sense of increasing disconnection (Brown, 2017). In a series of compelling Ted talks she emphasizes her belief that people need to develop the courage to stand alone in their values so that they can be with others, understand the value of their own voice, and not sacrifice who they are in their overarching need to belong. If we are to follow the example of Revans, such advice is invaluable information for business scholars whose modus operandi should be the discovery of what it takes for people to express their ideas and learning in times of change Group think as a silencing technique is unfortunately all too alive and well, encouraged through standardized testing and traditional human resource and organizational interventions.

Most of organizational theory is taught from a top down perspective. We teach leadership from the top. It is an important component of organizational development and human resource theory - transformational leadership to bring about change and transactional leadership to manage change. But this view of leadership has by its very definition a status quo component. It is based on how to make the existing paradigm of business or organization more efficient, not necessarily how to do things differently. Not only do we teach that this is the kind of leadership that matters, but it is built into our expectations of what leadership is. Our assumptions, often unspoken, are that if we can wait for the leaders to just get it, or if we can just hire the right person, then not only we will be saved but we will have someone to blame when things go wrong. This overlooks the fact that as human beings, we all have the capacity to be the right person - to understand and articulate the need for change. We can all be leaders in our own right. What we require for this to happen is for the right conditions to ask the right questions, and take the appropriate actions. As Mintzberg asks "if change is good, then how come our models of change hardly change?" He goes on, "are the best strategies formulated from on high...or do they form amidst the clutter of real life?" His recent blog is aptly titled "Transformation from the top? How about engagement on the ground?" (Mintzberg
Twog, Sept 15, 2017).

\section{THE ROLE OF UNIVERSITIES IN ACTION LEARNING}

One of the problems with business schools is that they find it difficult to move out of their preset agendas of what the various components of their curriculum maps should be. As Mintzberg notes, they fail on the business agenda count, as teaching schools, because what they teach is divorced from the reality of business (Mintzberg, 2004). Action Learning presents them with the opportunity to do things differently. Indeed, Mintzberg's own program which he describes in his book Managers not MBAs (2004) via McGill University in Montreal offered a real opportunity for people from various large organizations and businesses across the world to come together and share their management and leadership experiences and problems in the light of insightful comments and questions from others in similar situations. Revans himself, once he walked away from the Manchester Business School, worked in connection with five universities and 21 major businesses in Belgium (Revans, 1998). His Belgium project led to this country raising its industrial production beyond that of the US and Great Britain at the time. His main tool was action learning, organizing groups of managers into sets or groups of 4 to 8 people, all of whom had to work in the same manner as he himself had worked in the Cavendish Laboratories in Cambridge, asking each other difficult questions and then having to take action on their resolution The work over a number of years was both exhausting and exhilarating. When he told the story, he reiterated that participating in an action learning project not only changes the organization, it changes the persons involved as they start to peel off their own certainties and immerse themselves in the process of not knowing. "Those unable to change themselves cannot change what goes on around them" (Revans, 1998, p. 85). For the managers, their own most profound question came at the end of the process when one set member posed the following question, "what is an honest man and what need I do to become one?"(p. 85).

Other similar programs have been developed in conjunction with universities in the UK, and businesses and organizations in that country. One such program most recently involving this author is with the British Civil Service, currently 
confronting really complex business and organization problems stemming from changing demographics and cultures, technologies, and politics amongst other things. The bureaucratic government service everywhere is slow to change its ways of doing business, despite a plethora of new recruits who are university educated in the ways of management and change. Action learning programs where the participants ask the questions in conjunction with fellow set members, and then take action steps to move forward, can assist in changing that hard wired civil service mentality which is seemingly part of our brain synapsis. Having non university types act as set facilitators or coaches, and giving participants the opportunity to write about their learning and development in papers that can then be accredited by a university in terms of a rigorous learning experience at the master's level, is one way of capturing work based learning. The content of the papers will be determined by the questions posed by the participants and will be different for everyone participating in the program. As Mintzberg noted in his 2004 book, , such programs have been more popular in the UK than in North America. However, wherever popular, such a program is a way forward for universities to partner with organizations in the change process.

\section{AN ACTION LEARNING PROCESS IN ACTION}

And what about the professors who teach in universities? How available is the Action Learning process to drive their personal learning and organizational practice forward? A careful read of Revans's $A B C$ of Action Learning, which was first published in 1978, and then republished in 1998 in the Mike Pedler library by Lemos and Crane, provokes the following questions that anyone can consider as they work with others. The questions are intended to be helpful, driving both knowledge and organizational learning forward as changing context and circumstances impact business and strategy.

1) What is the main organization or business problem currently facing you that you would like to resolve? In determining this problem, note whether it is easy to define or difficult. What makes it difficult? And what makes it easy? What do you believe are the biggest barriers you face in stopping you from taking action?
2) Who would you consider as a fellow set member? In the ABCs of Action Learning Revans wrote of set members as comrades in adversity(p. 78., meaning that they are bound to each other through their commitment to action in the face of the problems they have defined. Revans believed and emphasized the role of the set to be mainly reporting, analysing and planning the real time action that is continually being taken by set participants in their operational backgrounds.

3) What actions are immediately possible for you, given your articulation of your problem? A useful tool here might be a Knowledge Map. Hale (2014,) describes knowledge mapping as a useful process to discover what tools or theories might be useful to apply to your problem before putting them into action. Knowledge mapping means

- Articulating and drawing a diagram of what you already know and what is easily accessible concerning the problem you have defined. This would be the ground. The sky refers to those available sources of knowledge or resources that are above ground but which can be pulled in.

- Finally what are the systems or programmes, often seen as barriers but which are frequently referred to as power and or political or cultural issues which are often left suppressed and underground?.

This process of knowledge mapping assists in helping people define what they know for sure, what they believe might be true underground, and what they believe could be true as they search the sky. Power, political values and culture are not issues always talked about in business schools. This process, when shared with other members of the set, is a powerful tool for viewing your problem from a different perspective and thus making visible action routes that would not have been clear before.

\section{CONCLUSION}

In a presentation at Salford University, Revans quoted the following story from the annals of Archie Cochrane, the father of functional medicine. It is a story which has great significance for we humans who, in our rush for scientific solutions and money-making endeavors, have sometimes forgotten as the very essence of human values 


\section{The Scene was a prisoner of war camp}

The ward was full so I put him in my room as he was moribund and screaming and I didn't want him to wake the ward.

I examined him. He had gross bilateral cavitation and a severe plural rib. I thought the latter was the cause of the pain and the screaming. I had no morphia, just asprin which had no effect. I felt desperate. I knew very little Russian then and there was no one in the ward who did. I finally instinctively took him in my arms, and the screaming stopped almost at once. He died peacefully in my arms a few hours later. It was not the pleurisy that caused the screaming but loneliness. It was a wonderful education about the care of the dying. I was ashamed of my misdiagnosis and kept the story secret.

The story reminds us that while we may desperately seek for scientific solutions to detract from immediate problems, the essence of action is determined by our core human values. Action learning, at its best is about the elevation of the human spirit in such a way that the enterprise becomes a learning system with everyone participating in its development. Although Revans was frequently writing about managers, his strong belief was that learning through action is a human obligation for growth. He saw action learning as bringing about interpersonal understanding that engendered self-awareness He believed that the organization that continues to express only the ideas of the past is not learning; that learning through action is essential if we are to not just cope with change but to actually lead it. This is a moral philosophy which necessitates honesty about one's self, starting from a position of not knowing, toward the discovery of fresh questions, real action beyond just thought, in a spirit of comradery, and for the overall purpose of doing good in the world. In short action learning can provide a powerful means to move ahead in problem solving. In so moving, it will change who we are, and conceivably change our world - for the better.

\section{REFERENCES}

Archie Cochrane with M Blyth, One Man's Medicine. Retrieved from: www.cochrane.org/docs/archieco.htm

Bowerman, J (2003), Leadership development through action learning: an executive monograph", Leadership in Health Services, Vol. 16, Issue 4, pp. 6-14

Brown, B. (2017), Braving The Wilderness: The Quest for True Belonging and the Courage to Stand Alone, Random House, New York

Brown B. ( March 16,2012) Listening to Shame, Ted Talks

Hale, R. and Bowerman, J. (2016) . Action Learning Questions: Making sense of organizational chaos, Journal of Eastern European and Central Asian Research, Vol.3 No. 2.

Hale, R. (2014). "Fundamentals of action learning: Knowledge mapping”, Training Journal, September, p. 15-17

Harari, Y.N.(2014) Sapiens: A Brief History of Humankind, Signal, A Division of Random House of Canada Limited.

Mintzberg, Henry, (2004). Managers not MBAs: A Hard Look at the Soft Practice of Managing and Management Development, BerrettKoehler Inc. San Francisco.

Mintzberg Twog, 2017, @ Mintzberg.Org

Revans, R. W. (1998), ABC of Action Learning. Empowering Managers to Act and Learn from Action. Lemos and Crane. UK.(first published in 1978.

Taubes, G. (2016), The Case Against Sugar. Alfred A Knopf, New York.

Teicholz, N. (2014). The Big Fat Surprise. Simon \& Schuster. US. 


\section{ABOUT THE AUTHOR}

Jennifer K. Bowerman, email:

jenniferbowerman404@gmail.com

Dr. Jennifer K. Bowerman is formerly an Assistant Professor in the Department of Organizational Development at MacEwan University in Edmonton, Alberta, and currently a Sessional Lecturer in International Business. She also serves as Editor of an International Journal entitled: Leadership in Health Services. Jennifer received a Bachelor degree in Sociology in England, and then a Masters Degree at the University of Saskatchewan before obtaining a doctorate in Management from Southern Cross University and International Management Centers specializing in Action Learning. She was privileged to study under Dr. Reg Revans at a month long seminar at the University of Salford in 1997 organized by Virginia Commonwealth University. 